Personalidade Acadêmica Homenageada:

Augustus B. Cochran III (Agnes Scott College)

\title{
INTERVENÇÃO DO ESTADO POR MEIO DA GOVERNANÇA CORPORATIVA: BREVE ESTUDO SOBRE SEUS REFLEXOS SOCIAIS E ECONÔMICO
}

\section{STATE INTERVENTION THROUGH CORPORATE GOVERNANCE: A BRIEF STUDY ON ITS SOCIAL AND ECONOMIC REFLEXES}

JAQUELINE MARIA RYNDACK

Advogada. Mestranda em Direito Empresarial e Cidadania pelo Centro Universitário Curitiba - UNICURITIBA. Especialista em Ministério Público - Estado Democrático de Direito, na área de concentração em Direito Penal, Fundação Escola do Ministério Público do Paraná - FEMPAR. E-mail: ryndack.jaqueline@hotmail.com

FÁBIO ANDRÉ GUARAGNI

Professor Orientador. Procurador de Justiça no MP-PR. Doutor e Mestre em Direito das Relações Sociais (UFPR). Professor de Direito Penal Econômico no Mestrado do UNICURITIBA. Professor de Direito Penal: FEMPAR, EMAP, CERS. E-mail: guaragni@mppr.mp.br

RESUMO

A Constituição Federal de 1988, em um primeiro momento, atribuiu ao Estado o papel de realizar materialmente algumas necessidades básicas para concreção do Princípio da Dignidade da Pessoa Humana. Deste modo, consta a obrigação de prestar serviços públicos, regulação econômica e social, incentivo e fomento estatal, de modo a buscar a concretização de uma sociedade solidária, comprometida com a minimização das desigualdades, promoção do 


\section{Personalidade Acadêmica Homenageada:}

\section{Augustus B. Cochran III (Agnes Scott College)}

desenvolvimento nacional, proteção do meio ambiente, erradicação da pobreza. Em meio à intensificação do combate à corrupção, através do Decreto oㅜ 8.420/2015, na Lei $n^{\circ}$ 9.613/1998 e na Lei № 12.846/2013, emerge nova roupagem para a intervenção do Estado enquanto agência de controle, preventiva e repressiva. Busca-se, nesse trabalho, meio de pesquisa bibliográfica, através do método dedutivo, analisar o papel que a governança corporativa tem como mecanismo de controle interno instado por ação estatal, bem como os seus reflexos sociais e econômicos na economia brasileira. Por resultados, definiu-se a governança corporativa como conjunto de práticas administrativas que buscam otimizar, no quadro de desempenho da empresa, a proteção não só dos sócios, mas de todas as demais partes interessadas: funcionários, fornecedores, clientes, credores, governos. Ela opera através da conformidade com o cumprimento das normas reguladoras e aprimoramento do modelo de gestão, transparência e facilitação do acesso às informações básicas, prestação de contas fundamentada em relatórios de auditoria e contabilidade vorazes, dentre outros parâmetros. Assim contextualizada, a governança corporativa é precioso mecanismo de proteção da ordem econômica. Esta percepção, aliada ao permissivo constitucional excepcional de intervenção estatal indireta na economia - art. 174, sob os valores e princípios do art. 170 -, legitima o Estado a instar e fomentar sua adoção pelos empreendedores particulares, notadamente entes coletivos, bem como criar eventuais sanções para a respectiva ausência. Cria-se uma moldura capaz de produzir sinergia entre agentes públicos e privados, em autêntica "hibridização" (NIETO MARTíN, 2013, p. 13), revelada em modelos de compliance derivados de autorregulação regulada, tornando o ambiente das trocas econômicas mais atraentes à entrada de capital, por produzir incrementos de confiança. Tudo viabiliza a geração de mais riquezas e a valorização do trabalho. Pelo viés dos reflexos sociais, nota-se que a governança corporativa atinge, de modo positivo, várias esferas do direito (a exemplo dos direitos trabalhistas, dos investidores no mercado de valores mobiliários, etc.), repercutindo positivamente na vida de cada indivíduo e na coletividade. 
Personalidade Acadêmica Homenageada:

Augustus B. Cochran III (Agnes Scott College)

PALAVRA-CHAVE: Intervenção Estatal; Governança Corporativa; Ordem

Econômica; Reflexo Econômico; Reflexo Social

\section{REFERÊNCIAS}

ANDRADE, Adriana; ROSSETTI, José Paschoal. Governança corporativa: fundamentos, desenvolvimento e tendências. 5. ed. São Paulo: Atlas, 2011.

BECK, Ulrich. La sociedad del riesgo mundial. Madrid: Paidós, 2008.

BORGES, Alexandre Walmott; CÔRREA, Andrey Lucas Macedo; PINHÃO, Karina Almeida Guimarâes; HENRIQUE JÚNIOR, Moacir. A violação à Ordem Econômica na Constituição de 1988 e à Lei Antitruste no exercício disfuncional da ação na defesa da propriedade intelectual. In Revista Jurídica. V. 02, n. 47. Curitiba: 2017, p. $335 \quad 362 . \quad$ Disponível em: <http://revista.unicuritiba.edu.br/index.php/RevJur/article/view/2038/1317>. Acesso em: 17/11/2018.

BRASIL. Constituição da República Federativa do Brasil de 1988. Disponível em: $<$ www.planalto.gov.br/ccivil_03/constituicao/constituicaocompilado.htm>. Acesso em: 17/11/2018.

Decreto no 8.420, de 18 de março de 2015. Regulamenta a Lei no 12.846, de 10 de agosto de 2013, que dispõe sobre a responsabilização administrativa de pessoas jurídicas pela prática de atos contra a administração pública, nacional ou estrangeira e dá outras providências. Disponível em: <www.planalto.gov.br/ccivil_03/_Ato2015-2018/2015/Decreto/D8420.htm>. Acesso em: 17/11/2018.

Lei no 12.846, de 1o de agosto de 2013. Dispõe sobre a responsabilização administrativa e civil de pessoas jurídicas pela prática de atos contra a administração pública, nacional ou estrangeira, e dá outras providências. Disponível em: <www.planalto.gov.br/ccivil_03/_ato2011-2014/2013/lei/112846.htm>. Acesso em: 17/11/2018.

Lei no 9.613, de 3 de março de 1998. Dispõe sobre os crimes de "lavagem" ou ocultação de bens, direitos e valores; a prevenção da utilização do sistema financeiro para os ilícitos previstos nesta Lei; cria o Conselho de Controle de Atividades Financeiras - COAF, e dá outras providências. Disponível em: <www.planalto.gov.br/ccivil_03/LEIS/L9613.htm>. Acesso em: 17/11/2018.

Supremo Tribunal Federal. Ação Direta de Inconstitucionalidade no

1.950. Relator: Eros Roberto Grau. Disponível em: $<$ www.stf.jus.br/jurisprudencia/IT/frame.asp?PROCESSO=1950\&CLASSE=ADI\&cod 
Personalidade Acadêmica Homenageada:

Augustus B. Cochran III (Agnes Scott College)

classe $=504 \& O R I G E M=I T \& R E C U R S O=0 \& T I P \_J U L G A M E N T O=M \& E M E N T A=223>$. Acesso: 17/11/2018.

CERVINI, Raúl e ADRIASOLA, Gabriel. El derecho penal de la empresa desde una visión garantista. Montevideo/Buenos Aires: BdF, 2005.

CORTINA, Adela. Ética de la empresa. Madrid: Trotta, 2005.

DAFT, Richard L. Administração. Trad. Harue Ohara Avritcher. São Paulo: Cengage Learning, 2010.

FELDENS, Luciano e DIETTRICH, Eduardo Dalla Rosa. A privatização da função investigatória nos delitos empresariais. In FELDENS, Luciano; ESTELLITA, Heloísa e WUNDERLICH, Alexandre. Direito Penal econômico e empresarial: Estudos dos grupos de pesquisa em Direito Penal Econômico e Empresarial da PUCRS e da FGV DIREITO SP. Rio de Janeiro: Lumen Juris, 2016.

GAMA, Tácio Lacerda. Contribuição de Intervenção no Domínio Econômico. São Paulo: Quartier Latin: 2003.

GUARAGNI, Fábio André. Desvios cognitivos e volitivos nas atividades empresariais como fatores criminógenos: aspectos etiológicos e programas de criminal compliance como mecânica de controle. In ARAUJO NETO, Felix; GIACOIA, Gilberto; MAISONNAVE, Germán Alberto Aller. Direito penal e constituição II. Disponível em: <www.conpedi.org.br/publicacoes/910506b2/bk7pbl14/5S426f06iUEW18sA.pdf>. Acesso em: 17/11/2018.

GRAU, Eros Roberto. A Ordem Econômica na Constituição de 1988. 14. ed. rev. atual. São Paulo: Malheiros, 2010.

INSTITUTO BRASILEIRO DE GOVERNANÇA CORPORATIVA. Disponível em: $<$ www.ibgc.org.br/governanca/governanca-corporativa>. Acesso em: 17/11/2018.

MARTÍNEZ-BUJÁN PÉREZ, Carlos. Derecho Penal Económico y de la Empresa. Valencia: Tirant lo Blanch, 2007.

MASSUDA, Adriana; COSTA, Lívia Martins. Governança corporativa e Responsabilidade Social: um estudo da relação entre tais práticas. In $1^{\text {o }}$ Congresso UFSC de Controladoria e Finanças. Anais. Universidade Federal de Santa Catarina. Santa Catarina, 2007. Disponível em: <http://dvl.ccn.ufsc.br/congresso/anais/1CCF/20090728135505.pdf>. Acesso em: $17 / 11 / 2018$. 
Personalidade Acadêmica Homenageada:

Augustus B. Cochran III (Agnes Scott College)

MENDES, Gilmar Ferreira. Direitos Sociais. In MENDES, Gilmar Ferreira; BRANCO, Paulo Gustavo Gonet. Curso de Direito Constitucional. 9. ed. rev. atual. São Paulo: Saraiva, 2014, p. $627-684$.

NIETO MARTíN, Adan. Introducción. In NIETO MARTÍN, Adan e ARROYO ZAPATERO, Luís. El derecho penal económico en la era compliance. Valencia: Tirant lo Blanch, 2013.

OLIVEIRA, Djalma de Pinho Rebouças de. Governança corporativa na Prática: Integrando Acionistas, Conselho de Administração e Diretoria Executiva na Geração de Resultados. 2. ed. São Paulo: Atlas, 2011.

PEREIRA, Antonio. N.; VILASCHI, Augusto. Governança corporativa e

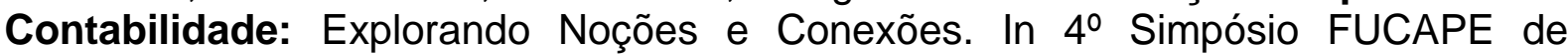
Produção Científica. Anais.Vitória: FUCAPE Business School, 2006. Disponível em: $<w w w . f u c a p e . b r / s i m p o s i o / 4 / a r t i g o s / a n t o n i o l . p d f>$. Acesso em: 17/11/2018.

PRADO, Luiz Regis. Direito Penal Econômico. 4. ed. rev., atual. e ampliada. São Paulo: Revista dos Tribunais, 2011.

REZENDE, Tiago Antunes; BENACCHIO, Marcelo. Desafios do programa compliance social de caráter trabalhista da empresa JBS S.A. In FARIA, Edimur Ferreira de; KFOURI NETO, Miguel. Intervenção Estatal, governança corporativa e Compliance no Combate à Corrupção. Disponível em: $<$ www.conpedi.org.br/publicacoes/02q8agmu/1m82505v/b8uKWI79UWOigz2Y.pdf>. Acesso em: 17/11/2018.

SANTOS, Roseli Rêgo. A importância da governança corporativa para a preservação da atividade empresarial no regime jurídico de recuperação de empresas. Anais do XXI Encontro Nacional do CONPEDI. Florianópolis: Fundação Boiteux, 2012, p. 5476-5499. Disponível em: $<$ www.publicadireito.com.br/artigos/?cod=f3e52c300b822a81>. Acesso em: 17/11/2018.

SANTOS JUNIOR, Althair Ferreira dos. Intervenção estatal sobre o domínio econômico: fiscalização, incentivo e planejamento. In Revista de Direito Público. V. 3 , n. 3. Londrina: 2008, p. 244-264. Disponível em: $<$ www.uel.br/revistas/uel/index.php/direitopub/article/viewFile/10975/9655>. Acesso em: 17/11/2018. 